\title{
Initial Outcome of Surgical Management of Parotid Gland Neoplasm
}

\author{
Sumon MMAK ${ }^{1}$, Afsana SD ${ }^{2}$, Hossain $\mathrm{MB}^{3}$
}

DOI: https:/ / doi.org/ 10.3329/ jafmc.v15i2.50839

\begin{abstract}
Introduction: Surgical excision is the gold standard for treatment of parotid gland neoplasm. But the complex relationship of the tumour to the facial nerve in the parotid gland makes the surgery very challenging.
\end{abstract}

Objective: To evaluate the initial outcome of parotid gland neoplasm surgery.

Materials and Methods: This cross-sectional observational study was conducted from January to December 2012 where 20 surgically treated patients with parotid gland neoplasm were selected by random sampling technique. They were followed up from 03 to 06 months to assess the minor post-operative complications.

Results: The study revealed that $35 \%$ of patients belonged to the $4^{\text {th }}$ decade of life. Pleomorphic adenoma constituted $85 \%$ of the tumours. Superficial parotidectomy was performed in $95 \%$ of cases. $40 \%$ of patients developed neuropraxia of the marginal mandibular branch of the facial nerve but all improved over a period of 3-6 months. 5\% had permanent facial nerve weakness. Frey's syndrome was observed in $20 \%$ of cases clinically but improved gradually. The rate of wound infection, parotid fistula and hypoesthesia of the skin over the ear lobule occurred in $10 \%, 5 \%$ and $20 \%$ cases respectively.

Conclusion: Safe and effective parotid gland surgery requires a clear understanding of the regional anatomy, the experience of the surgeon, meticulous surgical technique along with detailed preoperative informed consent for surgery to reduce post-operative complications and morbidity of the patient.

Key-words: Parotid neoplasm, Total conservative parotidectomy, Facial nerve, Frey's syndrome.

\section{Introduction}

Parotid gland neoplasm represents the most complex and diverse group of tumours encountered by the head neck surgeons. $85 \%$ of parotid neoplasms are benign ${ }^{1}$. Majority of benign tumours occurs in $3^{\text {rd }}$ and $4^{\text {th }}$ decade of life, whereas malignant tumours occur in $5^{\text {th }}$ and $6^{\text {th }}$ decade 2 . FNAC can differentiate malignant from benign salivary gland tumours with 80-90 percent accuracy ${ }^{3-5}$. Superficial parotidectomy is the treatment of choice for benign parotid gland tumours except when the tumour involves the deep lobe, where total conservative parotidectomy is done ${ }^{3}$. The complex relationship of the tumour with the facial nerve in the parotid gland makes the surgery very challenging. Effective management of these tumours demands an accurate histological diagnosis, the experience of the surgeon, detailed anatomical knowledge of the parotid glands and a clear understanding of the factors leading to postoperative complications.

\section{Material and Methods}

This cross-sectional observational study was conducted at the Department of Otolaryngology and Head-Neck Surgery, Combined Military Hospital Dhaka and Bangabandhu Sheikh Mujib Medical University (BSMMU) from 1st Jan 2012 to $30^{\text {th }}$ Dec 2012. A total number of 20 surgically treated patients with parotid gland neoplasm were included in this study by random sampling technique irrespective of age and sex. Patients with parotid swelling other than parotid neoplasm were excluded from the study. After evaluation of the tumour by clinical examination and specific investigations (like FNAC, USG, CT scan/MRI) a surgical plan was formulated. Surgical procedures adopted in this study were either superficial parotidectomy or total conservative parotidectomy. The specimen was sent for histopathology for final diagnosis and tumour typing. No facial nerve monitor was used during surgery. The postoperative follow up period of these patients ranged from 3 months to 6 months. Post-operative follows up was started immediately after recovery from surgery especially for any facial weakness (e.g. deviation of angle of mouth). The patient was followed up every day up to $7^{\text {th }}$ POD for wound condition, facial weakness, collection in the drain, seroma formation and development of Frey's syndrome. Stitches were removed on $7^{\text {th }}$ POD and the patient was discharged with advice. The patient was again followed up at $4^{\text {th }}$ week, $8^{\text {th }}$ week, $12^{\text {th }}$ week $16^{\text {th }}$ week, $20^{\text {th }}$ week and $24^{\text {th }}$ week. During this period, wound condition, facial palsy, parotid fistula, ear lobule numbness and signs of Frey's syndrome were looked for. Data were documented in a prepared data collection sheet and results were obtained statistically.

\section{Results}

Age distribution of the 20 parotid neoplasm patients ranged from 3165 years and the mean age was 37.2 years. Most patients $7(35 \%)$ were in $4^{\text {th }}$ decade and $6(30 \%) 5^{\text {th }}$ decade of life. The malignant tumour was found between the age group of 51-60 years. Male patients were $13(65 \%)$ and female $07(35 \%)$ with male to female ratio 1.86:1. Among the type of tumor Pleomorphic adenoma was $17(85 \%)$ and Warthin's tumour was $2(10 \%)$ and $1(5 \%)$ patients were Mucoepidermoid carcinoma (Table-I). About surgical procedure superficial parotidectomy was performed in 19(95\%) patients and conservative total parotidectomy in 1(5\%) patient (Figure-1). Regarding post-operative complications 9(45\%) patients developed facial nerve weakness, $8(40 \%)$ patients had a transient and isolated paresis of the marginal mandibular branch of the facial nerve was observed, permanent facial nerve weakness occurred in $1(5 \%)$ patient who complained of a deviation of the angle of the mouth, $4(20 \%)$ patients developed hypoesthesia of Great Auricular Nerve and Frey's syndrome was observed in 4(20\%) patients clinically. Wound infection occurred in 2(10\%) patients and parotid fistula

1. Lt Col Mohammad Misbah-Al-Kabir Sumon, MBBS, DLO, FCPS, Classified Specialist in ENT \& Head Neck Surgery, Combined Military Hospital, Momenshahi (E-mail: hisumon@yahoo.com) 2. Maj Sultana Dil Afsana, MBBS, MPH, BANENGR (CONSTR)-1 UNMISS 3. Maj Md Belal Hossain, MBBS, DLO, Graded Specialist in ENT \& Head Neck Surgery, Combined Military Hospital, Dhaka. 
occurred in $1(5 \%)$ patient with pleomorphic adenoma who had undergone superficial parotidectomy (Table-II).

Table-I: Distribution of patients by age, sex and type of parotid gland neoplasm $(n=20)$

\begin{tabular}{|l|l|c|c|c|c|}
\hline \multicolumn{2}{|c|}{$\begin{array}{c}\text { Characteristic } \\
\text { s }\end{array}$} & $\begin{array}{c}\text { Total } \\
\text { Cases } \\
\mathbf{n}(\%)\end{array}$ & $\begin{array}{c}\text { Pleomorphic } \\
\text { Adenoma } \\
\mathbf{n}(\%)\end{array}$ & $\begin{array}{c}\text { Warthin's } \\
\text { Tumour } \\
\mathbf{n}(\%)\end{array}$ & $\begin{array}{c}\text { Mucoepidermoid } \\
\text { carcinoma } \\
\mathbf{n}(\%)\end{array}$ \\
\hline \multirow{3}{*}{$\begin{array}{l}\text { Age } \\
\text { in } \\
\text { years }\end{array}$} & $\begin{array}{l}31-40 \\
\text { years }\end{array}$ & $7(35)$ & $7(35)$ & 0 & 0 \\
\cline { 2 - 6 } & $\begin{array}{l}41-50 \\
\text { years }\end{array}$ & $6(30)$ & $6(30)$ & 0 & 0 \\
\cline { 2 - 6 } & $\begin{array}{l}51-60 \\
\text { years }\end{array}$ & $5(25)$ & $3(15)$ & $1(5)$ & $1(5)$ \\
\cline { 2 - 6 } & $\begin{array}{l}61-70 \\
\text { years }\end{array}$ & $2(10)$ & $1(5)$ & $1(5)$ & 0 \\
\cline { 2 - 6 } & Total & $20(100)$ & $17(85)$ & $2(10)$ & $1(5)$ \\
\hline \multirow{2}{*}{ Sex } & Male & $13(65)$ & $10(50)$ & $2(10)$ & $1(5)$ \\
\cline { 2 - 6 } & Female & $7(35)$ & $7(35)$ & 0 & 0 \\
\hline
\end{tabular}

Type of Surgery

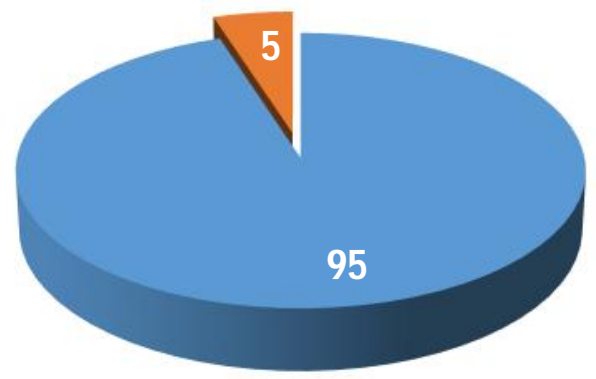

- Superficial Parotidectomy

Total Conservative Parotidectomy

Table-II: Distribution of cases according to post-operative complications $(n=20)$

\begin{tabular}{|l|c|c|c|c|}
\hline \multicolumn{1}{|c|}{ Complications } & $\begin{array}{c}\text { Pleomorphic } \\
\text { Adenoma } \\
\mathrm{n}(\%)\end{array}$ & $\begin{array}{c}\text { Warthins } \\
\text { Tumour } \\
\mathrm{n}(\%)\end{array}$ & $\begin{array}{c}\text { Mucoepidermoid } \\
\text { carcinoma } \\
\mathrm{n}(\%)\end{array}$ & $\begin{array}{c}\text { Total } \\
\text { cases } \\
\mathrm{n}(\%)\end{array}$ \\
\hline Immediate post op facial nerve weakness & $7(35)$ & 0 & $1(5)$ & $8(40)$ \\
\hline Permanent facial nerve weakness & $1(5)$ & 0 & 0 & $1(5)$ \\
\hline Parotid fistula & $1(5)$ & 0 & 0 & $1(5)$ \\
\hline Wound infection & 2 & 0 & 0 & $2(10 \%)$ \\
\hline Frey's syndrome & 3 & 0 & 1 & $4(20 \%)$ \\
\hline Hypoesthesia of Great Auricula Nerve & 3 & 0 & 1 & $4(20 \%)$ \\
\hline
\end{tabular}

\section{Discussion}

In this study 20 patients who were followed up postoperatively for a period 3-6 months. Late complications like recurrences were not included in this study. Pleomorphic adenoma was the commonest tumour encountered, constituting $85 \%$ of the parotid tumours in this study. Others included Warthin's tumour (10\%) and Mucoepidermoid carcinoma (5\%). These findings similar to other studies done by various authors $2,3,5$. The commonest site of the parotid tumour was superficial lobe 20(100\%). No deep lobe enlargement was found in this series. No patient presented with facial nerve palsy. In this series, $13(65 \%)$ patients were male and $07(35 \%)$ were female with male to female ratio $1.86: 1$. Most of the patients belonged to $4^{\text {th }}$ decade of life $7(35 \%)$ and the mean age was 37.2 years. Overall a transient facial palsy was present in $40 \%$ in patients. This is within the range of various publications showing an incidence of temporary facial deficits after conservative parotidectomy (from $18 \%$ to $65 \%)^{3,5-10}$. All 8 patients with postoperative facial nerve weakness recovered completely over 6 months. Normal function usually returns within 3-6 months, but it may take up to one year. It may be caused by nerve ischaemia, fatigue from excessive stimulation, stretching or haematoma formation.

The rate of permanent facial weakness in the present study is only in 1 patient with pleomorphic adenoma which is consistent with other studies. The reported incidence of permanent facial weakness is 0 $19 \%$ as per literature3,5-10. The most probable factor causing permanent facial nerve is direct injury or severe mechanical stretching especially in large tumour, malignancy and recurrent case. In this case, the tumour was very large and facial nerves branches were displaced and adherent with the tumour tissue. During follow up the patients were observed for clinical features of Frey's Syndrome (such as gustatory sweating or flushing) but no Starch lodine test was done. Frey's syndrome was found in 4(20\%) patients clinically out of which 3 cases recovered by 6 months with conservative treatment and 1 patient had partial recovery during the study period. The information found in the literature ${ }^{11-14}$ concerning the incidence of Frey's syndrome showed a great variation ranging from $2.6 \%$ to $97.6 \%$.

One patient (5\%) developed Parotid fistula during our study following superficial parotidectomy but healed spontaneously within 5 months. The reported incidence of post-parotidectomy fistula by Wax and Tarshis $\mathrm{L}^{15}$ and Laskawi et al16 was $14 \%$ and $4 \%$ respectively. This finding is also within the reported range of various western literature. A very common consequence after parotidectomy is hypoesthesia of the greater auricular nerve. Four patients (20\%) developed hypoesthesia of the skin over the ear lobule in our study amongst which 2 patients recovered by 6 months spontaneously and rest 2 patients had partial recovery during the study period. Two patients $(10 \%)$ developed wound infection in our series that were improved after taking antibiotics. Limitations of this study were small sample size, short study period and surgeries done by different surgeons in different hospitals. Long term follow-up is required for studying the tumour recurrence which was not possible in this study. 


\section{Conclusion}

To reduce the risk of complications especially iatrogenic facial nerve injury during parotid surgery, the surgeon must possess clear knowledge about regional surgical anatomy along with the precise surgical technique using multiple anatomicall and marks. Use of facial nerve monitor (FNM) and microscope may also be helpful. During preoperative consent for surgery, the patient must be clearly informed about various grades of facial nerve paralysis or paresis.

\section{References}

1. Joseph Califano et al. Benign Salivary Gland neoplasm's Otolaryngologic Clinics of North America 1999; 32(5):861-73.

2. Richard L. Fabian, 'Salivary Glands' Oxford Textbook of Surgery 1994; 2:2220-66.

3. Michael Gleeson, Roderick Cawson. Benign salivary gland tumors. Michael Gleeson. Scott-Brown's otolaryngology, Head and Neck surgery. $7^{\text {th }}$ ed. Hodder Arnold publisher, 338 Euston Road, London NW1 3BH 2008; 2:2475-92.

4. Andrew $\mathrm{S}$ Jones. Malignant tumors of salivary glands, Michael Gleeson, In Scott-Brown's otolaryngology, Head and Neck surgery. $7^{\text {th }}$ ed. Hodder Arnold publisher, 338 Euston Road, London NW1 3BH 2008; 2:2493-2521.

5. O'Brien CJ. Current management of benign parotid tumors: the role of limited superficial parotidectomy. Head and Neck 2003; 25:946-52.

6. Guntinas-Lichius O, Kick C, Klussman JP et al. Pleomorphic adenoma of the parotid gland: A 13-year experience of consequent management by lateral or total parotidectomy. European Archives of Otorhinolaryngology 2004; 261:143-6.
7. JMH Debets \& JDK Munting, Parotidectomy for parotid tumors. 19years experience from Netherlands. Br J Surgery 1992; 79:1159-61.

8. Mehle ME, Kraus DH, Wood BG et al. Facial nerve morbidity following parotid surgery for benign disease: the Cleveland Clinic Foundation experience. Laryngoscope 1993; 103:386-8.

9. Laccourreye $H$, Laccourreye $O$, Cauchois $R$ et al. Total conservative parotidectomy for primary benign pleomorphic adenoma of the parotid gland: A 25-year experience with 229 patients. Laryngoscope 1994; 104:1487-94.

10. Guntinas-Lichius $O$, Klussmann JP, Wittekindt $C$ et al. Parotidectomy for benign parotid disease at a university teaching hospital: Outcome of 963 operations. Laryngoscope 2006; 116:534-40.

11. Ross JAT. The function of the tympanic plexus as related to Frey's syndrome. Laryngoscope 1970; 80:1816e1833.

12. Laage-Hellman JE. Gustatory sweating and flushing. Aetiological implications of latent period and mode of development after parotidectomy. Acta Otolaryngol 1958; 49(4):306-14.

13. Orlando Guntinas-Lichius, Bettina Gabriel \& J Peter Klussmann. Risk of facial palsy and severe Frey's syndrome after conservative parotidectomy for benign disease: analysis of 610 operations. Acta Oto-Laryngologica 2006; 126:1104-9.

14. Rustemeyer J, Eufinger $\mathrm{H}$, Bremerich $\mathrm{A}$. The incidence of Frey's syndrome. Journal of Cranio-Maxillofacial Surgery 2008; 36:34e37

15. Wax M, Tarshis L. Post-parotidectomy fistula. J Otolaryngol 1991; 20:10-3

16. Laskawi R, Drobik C, Schonebeck C. Up-to-date report of botulinum toxin type a treatment in patients with gustatory sweating (Frey syndrome). Laryngoscope 1998; 108:381-4. 